\title{
Research on the Influence of Chinese Fiscal Decentralization on Regional Economy Against the Tax Distribution System
}

\author{
Ruijing Xuan \\ College of Economics and Management \\ Yunnan Agricultural University \\ Kunming, China 650201
}

\author{
Yuqin Zhang* \\ College of Economics and Management \\ Yunnan Agricultural University \\ Kunming, China 650201 \\ *Corresponding Author
}

\author{
Xuekun Li \\ College of Economics and Management \\ Yunnan Agricultural University \\ Kunming, China 650201
}

\begin{abstract}
Since the reform and opening up, fiscal decentralization reform is an important part of China's economic transformation, and is closely related to marketoriented reform. Under the tax distribution system, the reform and improvement of fiscal decentralization system has great theoretical and practical significance in promoting regional economic growth and studying the impact of Chinese fiscal decentralization on regional economy. In this paper, panel data of 27 provinces are used in the tax classification system and Eviews regression analysis are used to compare the economic growth differences of the four regions in China's fiscal decentralization system, east, central, west and northeast, to analyze the impact of Chinese fiscal decentralization on regional economic growth and draw the following conclusions: Fiscal revenue decentralization can promote the regional economic growth in the eastern region and inhibit that in the central region. Fiscal expenditure decentralization can inhibit the economic growth in the eastern and western regions and promote the economy in the central and northeastern regions.
\end{abstract}

Keywords-tax distribution system; fiscal decentralization system; regression analysis; regional growth disparity

\section{INTRODUCTION}

Fiscal decentralization reform has always been an important aspect of China's economic reform and is in line with market-oriented reform. Since 1978, the financial relationship between the central and local governments has gradually developed into two different stages: the transition period from 1980 to 1993 , and the centralization stage that implemented fiscal expenditure decentralization and fiscal revenue centralization after 1994. Reform of the tax distribution system was carried out nationwide in 1994. The tax distribution system is an important measure to establish the socialist market economic system, which is of great significance for improving the financial legal system, correctly handling the relationship between the central and local financial distribution, and promoting regional economic development.

Chinese and foreign scholars have conducted a lot of studies on the impact of fiscal decentralization on regional economy, and there are three main viewpoints: the first is that fiscal decentralization can promote regional economic growth. Brueckner (2006) established the Over Lapping Generation Model, which assumes that individuals invest human capital when they are young to increase their income and consumption utility level in old age. According to the model, decentralization system will increase residents' saving behavior, invite more investment and promote economic growth [1]. According to the theory of endogenous growth, Barro (1990) holds that the government can effectively reduce the production cost of enterprises and improve labor productivity by providing services and productive public goods, thus promoting economic growth. Oates (1999) proposed that there was an unclear single relationship between the degree of fiscal decentralization and national income, but there might be a positive correlation [3]. Lin Yifu et al. (2000) studied the impact of fiscal decentralization on per capita GDP in 28 Chinese provinces from 1970 to 1993 , and concluded that there was a positive correlation between fiscal decentralization degree and economic growth in China [4].

The second view holds that fiscal decentralization has an inhibitory effect on regional economic growth. Studies by Zhang Yan and Gong Liutang (2005) shows that fiscal decentralization inhibits economic growth in underdeveloped regions, which they think may be due to the lower operating efficiency and backward ideology of governments in economically underdeveloped regions [5]. Zhang \& Zou (1998) used the ratio of local fiscal expenditure to central fiscal expenditure as the indicator of fiscal decentralization, 
and analyzed the relationship between fiscal decentralization and economic growth based on China's provincial panel data from 1978 to 1992. They found that fiscal decentralization had a significant negative impact on economic growth [6].

The third view holds that there is no clear relationship between fiscal decentralization and economic growth. Bird (1993) studied the countries in transition in Eastern Europe and proposed that the relationship between fiscal decentralization and economic growth was not clear, and different countries had different influence paths [7]. Thornton (2007) studied OECD countries and concluded that there is no clear correlation between fiscal decentralization and economic growth given the fact that local governments' power abuse, rent-seeking behavior and endless irrational behaviors [8].

The influence of fiscal decentralization on regional economic growth is obviously different. Zhang Yan and Gong Liutang (2006) used five indicators to measure the degree of fiscal decentralization according to the data of provincial expert group from 1986 to 2002, and analyzed the impact of fiscal decentralization on overall and regional economic growth. The following conclusions are drawn: first, from the national perspective, before the tax distribution reform, local financial decentralization inhibited economic growth, while the tax distribution reform promoted economic growth. Secondly, from the regional perspective, fiscal decentralization has significant differences in the impact on regional economic growth in different regions. Fiscal decentralization has a more significant impact on economically developed regions, and the eastern region has more advantages than the central and western regions in fiscal decentralization [9]. Based on the provincial panel data from 1980 to 2004, Wen Jiaxiu et al. (2006) used the provincial per capita fiscal expenditure/total per capita fiscal expenditure budget to measure the decentralization index, and adopted the random effect regression method for analysis. The results show that fiscal decentralization can promote economic growth in China, but there are significant differences among different regions. The eastern region has more advantages in fiscal decentralization than the western region [10].

Based on previous studies, this paper analyzes the difference between fiscal decentralization and regional economic growth through fiscal revenue and fiscal expenditure within and outside the budget under the tax distribution system, studies the impact of fiscal decentralization on China's regional economic growth in the process of tax distribution reform, as well as the imbalance of regional economic development, and discusses how to better promote the balanced development of inter-regional economy. At the same time, it also provides reference for the reform of decentralization system in other countries in transition.

\section{DESCRIPTIVE ANALYSIS OF FISCAL DECENTRALIZATION AND REGIONAL ECONOMIC GROWTH IN ChInA Against THE TAX Distribution SYSTEM}

\section{A. Reform Process of Fiscal Decentralization in China}

The first generation of fiscal decentralization theory believes that income redistribution, resource allocation efficiency and macroeconomic stability are transmission channels for decentralization system to affect economic growth. The main idea is that local governments should allocate resources through the transfer payment system and reasonable tax system, and make them better meet local people's preference for services and public goods to maximize residents' welfare through competition among regional governments.

The second generation of fiscal decentralization theory shifted the focus from the supply of public goods to the local government behavior and economic growth, believing that the incentive of government officials is an important factor that must be considered. The core idea is how to stimulate local governments to improve their enthusiasm more effectively and increase the research on fiscal decentralization and regional economic growth.

A great attempt and innovation in the reform of China's fiscal system was the reform of tax distribution system in 1994. This reform defines the scope of government expenditure at all levels on the basis of clarifying the respective powers of the central and local governments. According to the principle of unification of administrative power and financial power, the revenue range of governments at all levels shall be divided into central tax, local tax and tax shared by central and local. Then tax authorities at two levels matching the tax distribution system are established respectively [11], and the transfer payment system and tax rebate system are established.

\section{B. Current Situation of Fiscal Decentralization and Regional Economic Growth in China}

1) Fiscal decentralization in different regions against the tax distribution system

Due to the obvious differences in regional location characteristics, resource endowments, history and culture, etc., the economic gap between regions is large, and the implementation effect of national policies is also different. This paper analyzes the regional differences of fiscal decentralization from the perspectives of fiscal revenue and fiscal expenditure. (See "Fig. 1" and "Fig. 2") The data source is China Statistical Yearbook and Finance Year Book of China. As can be seen from the figure, the eastern region has the highest degree of fiscal revenue decentralization, and the northeastern region ranks the second. The degree of fiscal revenue decentralization in central and western regions is similar and shows a trend of first decline and then rise. In recent years, the western region has surpassed the central region. After 2015, the degree of fiscal revenue decentralization in northeast China declined. In 2017, it was lower than that in central China, and the fiscal revenue 


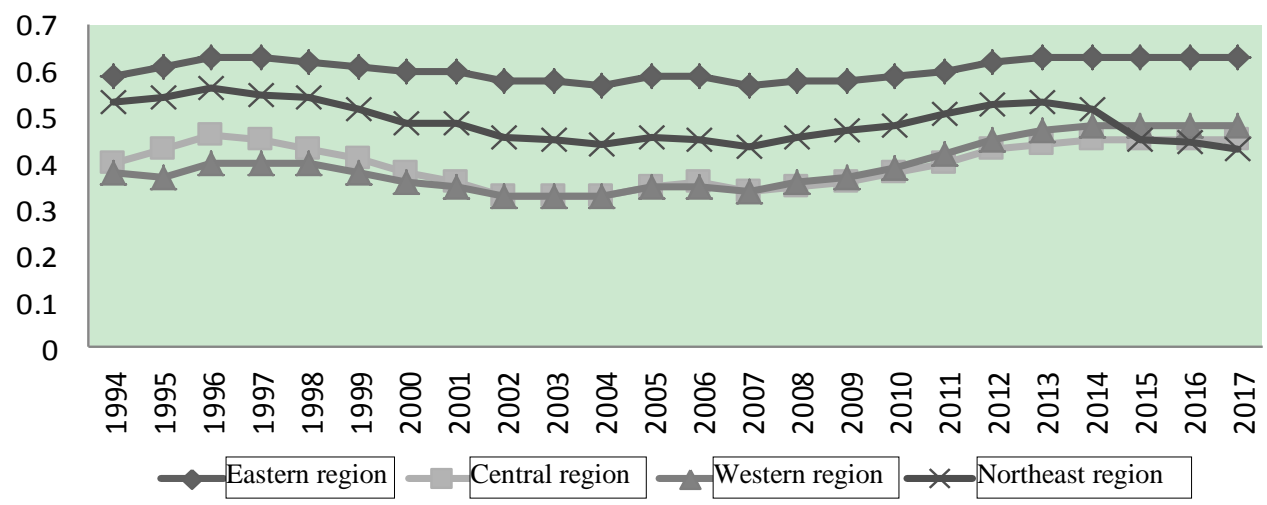

Fig. 1. Fiscal revenue decentralization in the east, central, west and northeast regions.

As can be seen from "Fig. 2", fiscal expenditure decentralization in northeast China reached the highest level in 1998 and began to decline in 2015. However, the degree of fiscal expenditure decentralization in eastern, central and western regions reached the lowest level in 2000 with overall upward trend and slow growth. The degree of fiscal expenditure decentralization is the highest in the eastern region and the lowest in the central region. Generally speaking, the degree of fiscal decentralization in these four regions is different.

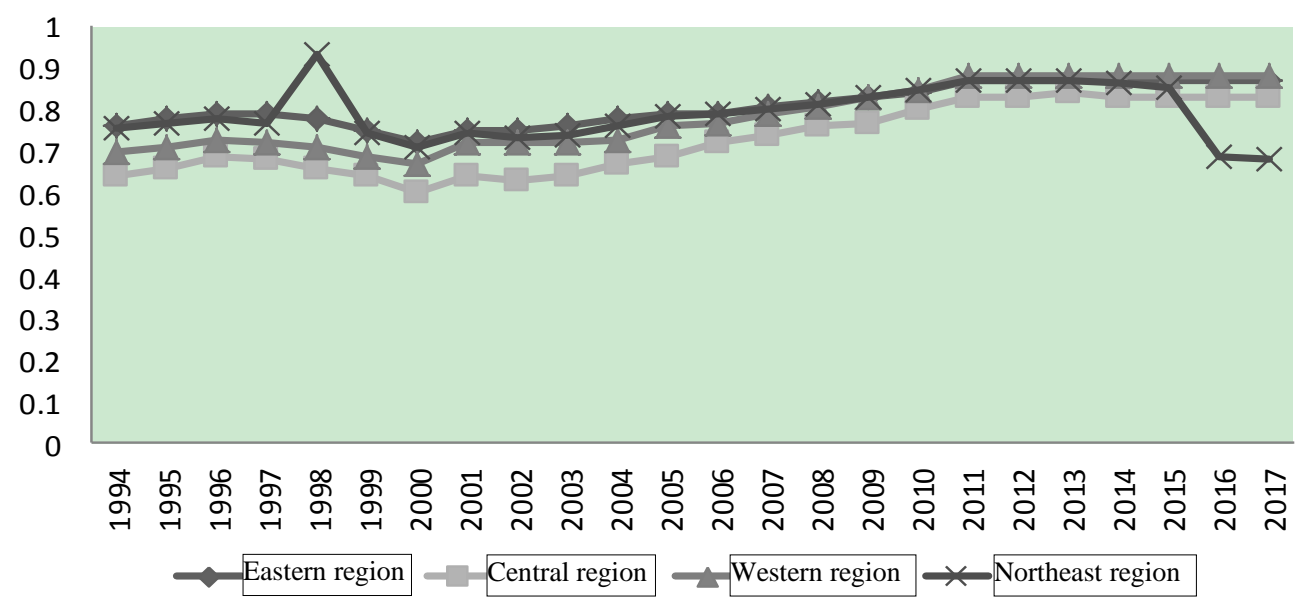

Fig. 2. Fiscal expedicture decentralization in the east, central, west and northeast regions.

2) The current situation of economic growth difference of each region

According to the figure, there are obvious differences in the economic growth of the four regions. The economic growth in the four regions declined from 1995 to 1999. After 1999, the economic growth of the eastern and central regions showed an upward trend, and the economic growth of the northeastern regions reached the peak of 28 percent in 2008. The economic growth decreased by $5 \%$ in 2016, and resumed growth in 2017. Eastern, central and western regions enjoyed similar economic growth. The economies of these four regions are more volatile from 2009 to 2012. In general, economic growth in northeast China fluctuated greatly from 1995 to 2017. 


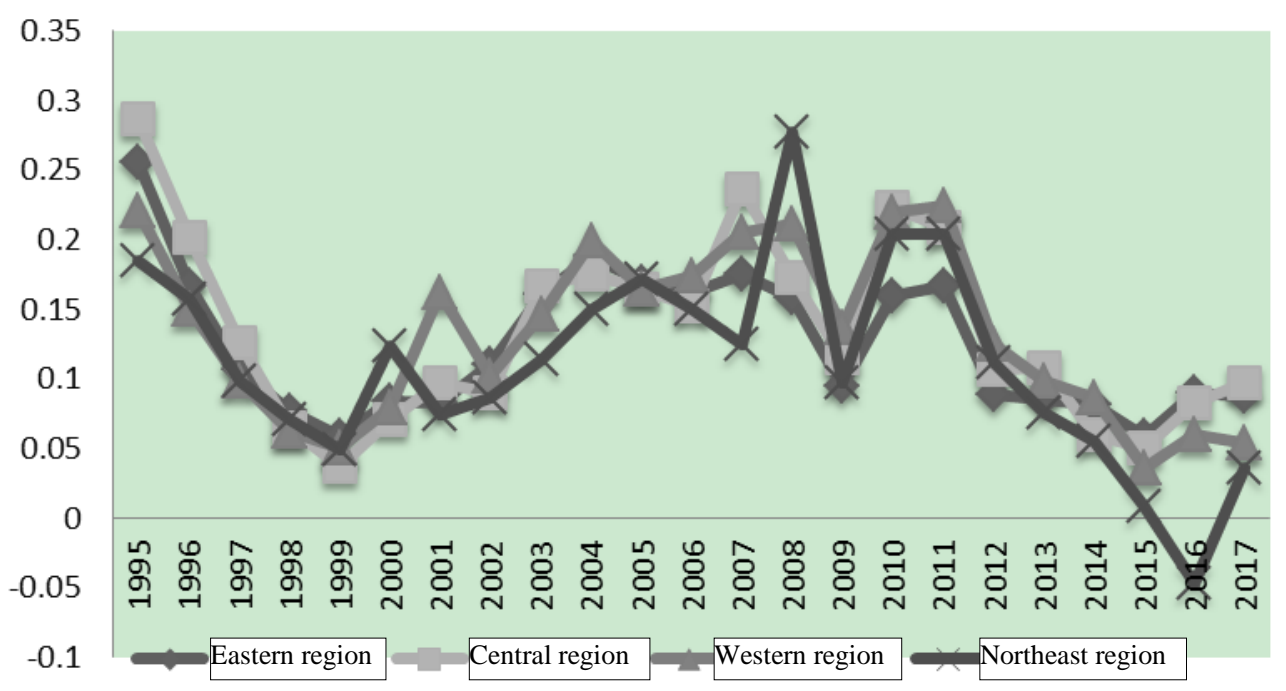

Fig. 3. Economic growth in the east, central, west and northeast regions.

\section{EMPIRICAL ANALYSIS OF THE IMPACT OF CHINA'S FISCAL DECENTRALIZATION ON REGIONAL ECONOMIC GROWTH AgaINST THE TAX DISTRIBUTION SYSTEM}

\section{A. Theoretical Model}

According to the theories of Barro and Zou and the relevant researches of Wen Xiujiao (2006), this paper assumes that the capital in the function consists of public capital and production capital, among which public capital is entirely provided by government expenditure, which consists of local government expenditure and central government expenditure. Cobb-Douglas production function is adopted in this paper.

$$
y=A k^{\partial} f^{\beta} s^{\gamma}
$$

$\mathrm{Y}$ represents output per capita, and A represents the factor of labor level, so let's take $\mathrm{A}=1$.

$\partial 、 \beta, \gamma \in(0,1), \partial+\beta+\gamma=1$. The tax rate $\tau=\mathrm{g} / \mathrm{y} f=$ per capita central government expenditure, $S=$ per capita local government expenditure, while $g={ }_{\text {per }}$ capita government expenditure. $g=f+s, \quad$ and $\partial 、 \beta 、 \gamma_{\text {serve as output elasticity. }}$

Suppose the economy is made up of many consumers, and each consumer needs to achieve utility maximization,

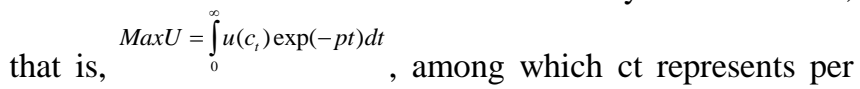
capita consumption, $p$ represents the time discount rate, and $\mathrm{e}^{-\mathrm{pt}}$ represents compound interest discount rate. The utility function satisfies the standard Ramsey function : $\mathrm{u}\left(\mathrm{c}_{\mathrm{t}}\right)=\frac{\mathrm{c}^{\mathrm{l}-\sigma}-1}{1-\sigma}$, among which $c_{t}$ represents consumption per head at $\mathrm{t}$, and $-\sigma$ represents marginal utility elasticity. $\lim _{\mathrm{t} \rightarrow \infty} \frac{c_{t}^{1-\sigma}}{1-\sigma} e^{-p t}=\lim _{t \rightarrow \infty} \frac{c_{0}^{1-\sigma}}{p} e^{-|p-q(1-\sigma)| t}=0$

$\mathrm{p}-\mathrm{q}(1-\sigma)>0$, and utility has a boundary, so the consumer dynamic constraint is $\frac{d k}{d t}=(1-\tau) y-c=(1-\tau) k^{\alpha} f^{\beta} s^{\gamma}-c$

The authors build the equation to solve the problem: $H=\frac{C^{1-\sigma-1}}{1-\sigma}+\lambda\left[(1-\tau) k^{\alpha} f^{\beta} s^{\gamma}-c\right]$.

The first prerequisite of the optimal solution of the above equation is: $\frac{\partial H}{\partial K}=P \lambda-\lambda$

Extended Simultaneous Equations is $c^{-\sigma}=\lambda, \lambda=p \lambda-(1-\tau) \partial k^{\partial-1} f^{\beta} s^{\gamma}$. The authors finally found out $\frac{y}{k}=k^{\partial-1} f^{\beta} s^{\gamma}=\frac{g}{\tau k}, k=\left(\frac{y}{f^{\beta} s^{\gamma}}\right)^{\frac{1}{\partial}}$. Plugged in the above formula, the authors realized $\lambda=\mathrm{p} \lambda-\lambda(1-\tau) \tau^{\frac{1-\partial}{\partial}} \partial\left(\frac{f}{g}\right)^{\frac{\beta}{\partial}}\left(\frac{s}{g}\right)^{\frac{\gamma}{\partial}}$, and per capita income growth rate $=$ per capita consumption growth rate: $g_{y}=g_{c}=\frac{\mu-p}{\sigma}$, among which $\mu=(1-\tau) \tau^{\frac{1-\partial}{\partial}} \partial\left(\frac{f}{g}\right)^{\frac{\beta}{\partial}}\left(\frac{s}{g}\right)^{\frac{\gamma}{\partial}}$.

From the above relation, it can be seen that per capita output ratio is not only related to interest rate $\tau$, but also related to the level of fiscal decentralization $\frac{s}{g}$.

\section{B. Econometric Model Setting and Variable Declaration}

According to the above theoretical model, per capita output is related to fiscal decentralization. Considering the 
FD2=per capita budgetary expenditure of each province / (per capita budgetary expenditure of each province + per capita expenditure of central government)

This paper divides the 27 provinces and autonomous regions (excluding municipalities directly under the central government) into four parts: east, central, west and northeast. Hebei, Shandong, Jiangsu, Zhejiang, Fujian, Guangdong, and Hainan belong to the eastern region. Shanxi, Henan, Anhui, Jiangxi, Hubei, and Hunan belong to the central region. Inner Mongolia, Shaanxi, Ningxia, Gansu, Qinghai, Xinjiang, Sichuan, Guizhou, Yunnan, Guangxi and Tibet belong to the western region, while Liaoning, Jilin and Heilongjiang belong to the northeastern region. The data in this paper are from China Statistical Yearbook and Finance Year Book of China.

\section{Empirical Analysis}

This paper adopts the panel data of 27 provinces from 2005 to 2017 under the tax distribution system to analyze the impact of fiscal decentralization on the regional economy in the east, central, west and northeast of China, and uses Eviews for regression analysis. The data are from China Statistical Yearbook and Finance Year Book of China.
FD1=per capita budgetary revenue of each province / (per capita budgetary revenue of each province + per capita revenue of central government)

TABLE I. SUMMARY OF REGRESSION RESULTS

\begin{tabular}{|c|c|c|c|c|}
\hline $\begin{array}{c}\text { Explanatory } \\
\text { Variable } \\
\end{array}$ & Eastern Region & Central Region & Western Region & Northeastern Region \\
\hline FD1 & $\begin{array}{l}0.3912 * * \\
(-1.9922)\end{array}$ & $\begin{array}{r}-1.5647 * * * \\
(-5.4275)\end{array}$ & $\begin{array}{l}-0.0457 \\
(-0.5740)\end{array}$ & $\begin{array}{l}0.0169 \\
(0.1627)\end{array}$ \\
\hline FD2 & $\begin{array}{c}-0.3663 * \\
(-1.8428)\end{array}$ & $\begin{array}{c}0.4270^{* *} * \\
(2.2962)\end{array}$ & $\begin{array}{c}-0.1844 * * \\
(-2.0024)\end{array}$ & $\begin{array}{r}2.3119 * * * * \\
(9.1110)\end{array}$ \\
\hline $\mathrm{L}$ & $\begin{array}{c}-0.1539 \\
(-1.3841)\end{array}$ & $\begin{array}{l}-0.0066 \\
(-0.0482)\end{array}$ & $\begin{array}{l}0.0586 \\
(0.4092)\end{array}$ & $\begin{array}{r}-0.1221 * * * * \\
(-6.7935)\end{array}$ \\
\hline $\mathrm{K}$ & $\begin{array}{c}0.1461 * * \\
(2.0742)\end{array}$ & $\begin{array}{l}-0.0048 \\
(-0.0499)\end{array}$ & $\begin{array}{r}0.3200^{* * * *} \\
(4.6299)\end{array}$ & $\begin{array}{r}-0.1700 * * * * \\
(-7.8752)\end{array}$ \\
\hline TAX & $\begin{array}{l}0.0012 \\
(0.2688)\end{array}$ & $\begin{array}{r}0.0223 * * * \\
(3.6146)\end{array}$ & $\begin{array}{l}-0.0012 \\
(-0.4730)\end{array}$ & $\begin{array}{r}-0.0148 * * * \\
(-3.1614)\end{array}$ \\
\hline $\mathrm{C}$ & $\begin{array}{r}0.5907 * * * \\
(4.2612)\end{array}$ & $\begin{array}{l}0.1085 \\
(1.2669)\end{array}$ & $\begin{array}{r}0.2643 * * * \\
(3.3475)\end{array}$ & $\begin{array}{r}-1.6296 * * * \\
(-7.6278)\end{array}$ \\
\hline R2 & 0.4662 & 0.6974 & 0.2648 & 0.9921 \\
\hline Adjust-R2 & 0.3919 & 0.6523 & 0.2380 & 0.9857 \\
\hline F-statistics & $6.2743 * * *$ & $15.446^{* * *} *$ & $9.8704 * * *$ & $156.132 * * *$ \\
\hline Hausman test & fixed effects model & fixed effects model & random effects model & random effects model \\
\hline Obs & 91 & 78 & 143 & 39 \\
\hline
\end{tabular}

According to the above regression results including labor growth rate ("Table I"), fixed asset growth rate and average tax rate, the regression coefficient in the eastern region is 0.3912, which is significant at 5\%, indicating that FD1 in the eastern region has a significant role in promoting the economy. The regression coefficient in the central region is 1.5647 , which is significantly correlated at $1 \%$, indicating that FD1 in the central region also has a significant inhibitory 
effect on regional economy. The regression coefficients in the western region and the northeast region are -0.0457 and 0.0169 respectively. The effect of FD1 on economic growth in western China was negative, but the regression results were not significant, while the effect of FD1 on economic growth in the northeast region was positive but the regression result was not significant. FD2 in the eastern region is negative, which is significant at $10 \%$, indicating that fiscal expenditure decentralization in the eastern region has a significant inhibitory effect on regional economic growth. The regression coefficients of the central and northeast regions are positive and significantly correlated at the level of $5 \%$ and $1 \%$ respectively, indicating that fiscal expenditure decentralization has a significant promotion effect on regional economic growth in the central and northeast regions, while FD2 in the western region has a significant inhibitory effect on regional economy. The labor growth rate in the northeast has a significant inhibitory effect on economic growth, and the regression results in the east, central and western regions are not significant. The growth rate of fixed capital can significantly promote the economic growth in the eastern and western regions and restrain the economy in the northeast. Tax rates promote the economy of the central region and inhibit that of the northeast.

\section{CONCLUSIONS AND RECOMMENDATIONS}

\section{A. Conclusions}

Based on the decentralization of fiscal revenue and fiscal expenditure after the reform of tax distribution system, this paper draws the following conclusions with the panel data of each province: Fiscal revenue decentralization is positively related to the economic growth of the eastern region and has a promoting effect, which benefits from the solid economic foundation and fiscal revenue of the eastern region and has an inhibiting effect on the economy of the central region. However, fiscal expenditure decentralization has an inhibitory effect on economic growth in the eastern and western regions. Excessive government investment and purchase has produced a huge crowding out effect on private investment and consumption, distorting market allocation, hindering economic structural adjustment, and ultimately affecting economic growth. Fiscal expenditure decentralization plays an obvious role in promoting economic growth in central and northeastern regions. Although fiscal revenue decentralization and fiscal expenditure decentralization have widely different effects on economic growth, overall speaking, since the reform of the tax distribution system, fiscal revenue decentralization has narrowed the differences in economic growth in the east, central, west and northeast regions to some extent, and promoted the growth in the central and western regions.

\section{B. Recommendations}

1) Establishing a scientific and standardized fiscal decentralization system

The reform of tax distribution system in 1994 achieved the original goal and laid the framework for the operation of the fiscal mechanism. However, it also had many shortcomings, such as the incomplete reform and the absence of a unified, transparent and fair transfer payment system in the implementation process. At present, only "budgetary fiscal revenue" is counted in China. However, the scale of extrabudgetary revenue is expanding rapidly, and the structure is becoming more diversified and difficult to control [13]. There is neither quantitative statistical measure nor effective institutional constraint on these extrabudgetary incomes. If not paid attention to, it will lead to distortion of the price mechanism, market mechanism and credit mechanism, which is not conducive to the long-term stable development of the economy. Therefore, it is necessary to clearly understand the nature of extrabudgetary funds, gradually improve the administrative institutional fee bill management system of local governments at all levels, strengthen the control over extrabudgetary funds, strengthen the calculation and statistics of fiscal accounts, increase oversight over the sources and structure of government revenue, and strengthen effective management of extrabudgetary income. Therefore, it is necessary to establish a scientific and standardized fiscal decentralization system, balance fiscal decentralization and centralization, and make local governments realize the balance of financial power and administrative power.

2) Reforming the single mechanism for assessing GDP and standardizing government functions

In recent decades, the central government mainly assessed the performance of local governments with the help of GDP index, which led to the phenomenon of championship promotion in local governments and the fierce horizontal competition among local governments, resulting in unreasonable expenditure structure. At the same time, there is a serious phenomenon of local protectionism in all jurisdictions, which greatly inhibits the flow of production factors such as talents and capital, thus hindering the rational development of the economy. The government should maintain market order, define its own functions, and withdraw from productive activities in order to better provide public goods and services [14]. Therefore, it is necessary to establish a sound supervision mechanism of laws and regulations to investigate the governance ability of local governments in a more reasonable, scientific and comprehensive way, change the original single GDP assessment mechanism, restrain local government officials' idea and impulse to intervene too much in the economy, change government functions, improve government management ability and build a service-oriented government.

3) Continuing to deepen government institutional reform and streamline administrative expenses

In the central and western regions, there is a common phenomenon that the daily administrative expenses increase too much and the proportion is too high. It has become a fact that the reform of administrative system lags behind the reform of economic system. In the central and western regions, there are problems such as unreasonable administrative expenses, overstaffed local government agencies and excessive financial burden. This also indirectly reflects the deficiency of local government in management structure, expenditure habit, idea and etc. The cost of 
[8] Thornton J. Fiscal Decentralization and Economic Growth Reconsidered [J]. Journal of Urban Economics. 2007(61): 64-70.

administration is too high, which directly affects the cost of science, education, culture and health and produces a strong crowding out effect. Based on the endogenous growth theory, education investment and technological progress are the ultimate driving forces to achieve sustained economic growth. Long-term insufficient expenditure on science, education, culture and health is not conducive to local economic development and industrial structure upgrading. Such problem is common in the central and western regions. Therefore, local governments should deepen the reform of government institutions, improve the efficiency of administrative expenditure, strengthen the management function of the government, and pay more attention to the input of science, education, culture and health [15].

4) Continuing to deepen the reform of the transfer payment system and promote inter-regional equalization

Fiscal transfer payment can effectively overcome the vertical and horizontal imbalance of inter-regional fiscal revenue and expenditure, narrow the gap in inter-regional economic growth, and effectively guide local governments to maximize the welfare of residents under their jurisdiction. As the gap in economic growth between different regions in China has widened, it is necessary to bridge the gap in fiscal revenue between backward and developed regions through transfer payments, promote the balance of fiscal revenue and expenditure among regions, provide financial support for the central and western regions, and promote coordinated economic growth across the country. Transfer payments can follow both horizontal and vertical model. On the one hand, local governments have shouldered a lot of fiscal expenditure responsibilities, and their financial powers and administrative powers are not matched, which requires the central government to make vertical transfer payments to lower-level local governments, especially in the central and western regions and regions with excessive debt ratio [16]. On the other hand, as the economic development and income level of the eastern region increases, fiscal revenue will flow horizontally to the central and western regions in the form of transfer payments to promote the level of public services in the central and western regions and narrow the economic growth gap with eastern region.

\section{REFERENCES}

[1] Tiebout, Charles M. A Pure Theory of Local Expenditures. Journal of Political Economy. 1956: 416-424.

[2] Barro, R.J. Government Spending in A Simple Model of Endogenous Growth [J]. Journal of Political Economy. 1990(98), No.5: 103-126.

[3] Oates, W. E. Fiscal Federalism. New York: Harcourt Brace Jovanovich. 1972.

[4] Lin Yifu, Liu Zhiqiang. China's Fiscal Decentralization and Economic Growth [J]. Journal of Peking University(Humanities and Social Sciences), 2000, (04): 5-17. (in Chinese)

[5] Zhang Yan, Gong Liutang. The Fenshuizhi Reform, Fiscal Decentralization, and Economic Growth in China [J]. China Economic Quarterly. 2005, 5(1): 75-108. (in Chinese)

[6] Zhang T, Zou H F. Fiscal Decentralization, Public Spending, and Economic Growth in China [J]. Journal of Public Economics. 2001,67(2): 221- 240.

[7] Bird R. Threading the Fiscal Labyrinth: Some Issues in Fiscal Decentralization [J]. National Tax Journal. 1993(46): 207-227.
[9] Zhang Yan, Gong Liutang. The Fenshuizhi Reform, Fiscal Decentralization, and Economic Growth in China $[\mathrm{J}]$. China Economic Quarterly. 2006 (1): 75-108. (in Chinese)

[10] Wen Jiaoxiu. China's Fiscal Decentralization and Economic Growth - Empirical Study Based on Provincial Panel Data [J]. Modern Economic Science. 2006(5). (in Chinese)

[11] Qian Yingyi. Incentive Theory and Financial Reform in China [J]. Financial Digest. 1997, (02): 24-25. (in Chinese)

[12] Qiao Baoyun. Growth Versus Equality: A Study of Fiscal Decentralization Policy in China [M]. Beijing: People's Publishing House. 2002. (in Chinese)

[13] Sun Yankun. A Study on the Relationship Between Fiscal Decentralization and the Quality of Regional Economic Growth [D]. Huaqiao University. 2016.6:29-33. (in Chinese)

[14] Shen Kunrong, Fu Wenlin. The Relationship Between China's Decentralized System in Finance and Regional Economic Growth [J]. Management World. 2005, (1): 31-39. (in Chinese)

[15] Su Li. The Division of Power between the Central and Local Governments in Contemporary China: Reinterpretation of Chapter Five of "On the Ten Prominent Relations" by Mao Zedong [J]. Social Sciences in China. 2004 (2): 42-55. (in Chinese)

[16] Wang Shaoguang. Sound System Design: the Key to Correctly Handle the Cooperative Relationship Between the Central and Local Government [J]. International Economic Review. 1997, (Z1): 32-35. (in Chinese) 